E3S Web of Conferences 1, 20010 (2013)

DOI: $10.1051 / \mathrm{e} 3$ sconf/20130120010

(c) Owned by the authors, published by EDP Sciences, 2013

\title{
Mineral phases containing heavy metals in the suspended dust from Budapest, Hungary
}

\author{
$\underline{\text { P. Sipos }}{ }^{1}$, E. Márton ${ }^{2}$, T. Németh ${ }^{1}$, V. Kovács Kis ${ }^{3}$, Z. May ${ }^{4}$ and Z. Szalai ${ }^{5}$
}

${ }^{1}$ Institute for Geological and Geochemical Research, Research Centre for Astronomy and Earth Sciences, Hungarian Academy of Sciences, H-1112 Budapest, Budaörsi út 45, HUNGARY, sipos@geochem.hu, ntibi@geochem.hu

${ }^{2}$ Paleomagnetic Laboratory, Geological and Geophysical Institute of Hungary, H-1145 Budapest, Columbus utca 17-23, HUNGARY, paleo@mfgi.hu

${ }^{3}$ Institute of Technical Physics and Materials Science, Research Centre of Natural Sciences, Hungarian Academy of Sciences, H-1121 Budapest, Konkoly-Thege Miklós út 29-33, HUNGARY, kis@mfa.kfki.hu

${ }^{4}$ Institute of Materials and Environmental Chemistry, Research Centre of Natural Sciences, Hungarian Academy of Sciences, H-1025 Budapest, Pusztaszeri út 59-67, HUNGARY, mzozo@chemres.hu

${ }^{5}$ Geographical Institute, Research Centre for Astronomy and Earth Sciences, Hungarian Academy of Sciences, H-1112 Budapest, Budaörsi út 45, HUNGARY, szalai@mtafki.hu

\begin{abstract}
The mineralogy, geochemistry and magnetic properties of total suspended particulate (TSP) matter in Budapest, Hungary were studied to identify their heavy metal-bearing mineral phases. Amorphous organic matter, magnetite, salts as well as mineral phases characteristic of the surrounding geology are the main components of the TSP. They show significant enrichment in several heavy metals, such as $\mathrm{Zn}$ (up to $19046 \mathrm{mg} / \mathrm{kg}$ ), $\mathrm{Pb}$ (up to $3597 \mathrm{mg} / \mathrm{kg}$ ), $\mathrm{Cu}$ (up to $699 \mathrm{mg} / \mathrm{kg}$ ) and Mo (up to $53 \mathrm{mg} / \mathrm{kg}$ ). The most frequent heavy metal-bearing mineral phases are spherular or xenomorphic magnetite particles containing $2-3 \mathrm{wt} \% \mathrm{~Pb}$ and $\mathrm{Zn}$. They often form aggregates and are closely associated with soot and/or clay minerals. The size of these particles is rarely below $30 \mathrm{~nm}$. $\mathrm{Cu}$ and Mo could be associated to magnetite too. Clay minerals and mica particles may also contain significant amount of $\mathrm{Zn}$ (up to $5 \mathrm{wt} \%$ ). Additionally, $\mathrm{ZnO}$ and $\mathrm{ZnCO}_{3}$ particles were found in the sample with highest $\mathrm{Zn}$ content and our data suggest the potential association of $\mathrm{Pb}$ and carbonates, as well. Magnetite particles are resistant to weathering releasing its toxic components slowly to the environment, while layer silicates (and carbonates) may be the potential source of mobile toxic metals in the TSP.
\end{abstract}

Key words: urban dust, air pollution, magnetite, clay minerals, lead, zinc

\section{Introduction}

Airborne particulate matter has been widely associated with health disorders as presented by numerous studies. In the past, their estimates have tended to be of total suspended particles, which are not clearly defined particle fractions. On the contrary, recent attention has focused on the gravimetric measurement of the PM10 and PM2.5 fractions of airborne particulate matter as these fractions may cause the most intense health damage due to their easy penetration to the innermost regions of the lung. However, particles with a diameter of up to 100 $\mu \mathrm{m}$ can be inhaled by nose or mouth, and those below 32 $\mu \mathrm{m}$ may reach the bronchial tubes too.

So in spite of the fact that the relatively large grain size of the total suspended particulate (TSP) matter in the urban air involve smaller health risk than PM10 or PM2.5 fractions, their study is also of primary importance. They can be both ingested and inhaled and they may cause health damage due to their size, shape or toxic components.

In this study detailed mineralogical, geochemical and magnetic analyses were carried out to identify and characterize the mineral phases associated with heavy metals (primarily $\mathrm{Pb}$ and $\mathrm{Zn}$ ) in the total suspended particulate matter from Budapest, Hungary.

\section{Materials and Methods}

Samples were collected from the air filters placed in the respiration channels used for the air supply of the methane-heated turbines in four thermal power stations 
in Budapest, Hungary (Kelenföld /KF/, Köbánya /KB/, Újpest /UP/, Csepel /CS/). The filters are in use until their transmission is high enough (up to several months or even a year). The amount of the air transmitting through the filters may be as high as several thousands of $\mathrm{m}^{3} / \mathrm{h}$, which means that more than one million $\mathrm{m}^{3}$ of air may be filtered in a month using such a filter. The $60 \times 60$ $\mathrm{cm}$ large air respiration slots are generally placed at 5-15 $\mathrm{m}$ height so the contribution of soil to TSP material is minimal. However, contribution of soot and carbonaceous particles may be overrepresented at this sampling method due to the result of methane combustion in the thermal power stations when compared to urban particles collected at different kind of sampling sites.

Altogether nine TSP samples were analyzed: 4 from KE, 2 from KB, 2 from UP and 1 from CS thermal stations. Samples were removed from the filters mechanically. Large plant and animal debris were removed by passing them through a $2 \mathrm{~mm}$ sieve. Particle size distribution of the samples was determined by a Fritsch Analysette Microtech A22 laser diffraction analyzer. The bulk samples were characterized for their mineralogical composition by a Philips PW 1710 X-ray diffractometer. Concentration of 18 chemical elements (As, Ba, Ca, Cr, Cu, Fe, K, Mn, Mo, Ni, Pb, Rb, S, Sr, Ti, $\mathrm{V}, \mathrm{Zn}, \mathrm{Zr}$ ) in the bulk samples were analyzed by a Thermo Niton XL3 type X-ray fluorescent spectrometer. Magnetic susceptibility analyses were carried out using a KLY-2 Kappabridge instrument which operates with one frequency. The samples were also analyzed with an MFK1 instrument operating with three frequencies in order to estimate the contribution of superparamagnetic particles (with size below $0.03 \mu \mathrm{m}$ ). High resolution analytical electron microscopy and selected area electron diffraction analyses were carried out to characterize the mineralogical and chemical composition of individual mineral particles in the samples with special emphasis on those containing heavy metals. The samples were suspended in ethanol and then they were dropped onto a holey carbon coated $\mathrm{Cu}$ grid for the analyses. The measurements were performed on a Philips CM 20 transmission electron microscope with a LaB6 filament, equipped with a Noran energy dispersive spectrometer. We pretended to analyze only one discrete particle in each case, which could be confirmed from the corresponding diffraction pattern. The identification of the individual mineral phases was performed based on their diffraction pattern and chemical composition.

\section{Results and Discussion}

The samples consist of particles with size generally below $50 \mu \mathrm{m}$ with a maximum frequency at around 10-12 $\mu \mathrm{m}$. A slight secondary maximum at $3 \mu \mathrm{m}$ also appears for each sample. Additionally, samples from the UP thermal station also show a tertiary maximum at around $35 \mu \mathrm{m}$. Between 45 and $80 \%$, as well as 12 and $25 \%$ of their particles belong to the PM10 and PM2.5 fractions, respectively. The main mineral components of the TSP samples primarily reflect the geological characteristics of the sampling areas. They consist mostly of quartz (20-30\%), carbonates (dolomite and calcite; $10-20 \%$ ), clay minerals $(5-15 \%)$ and feldspars (around $5 \%$ ). Additionally, phases basically of anthropogenic origin also appear.

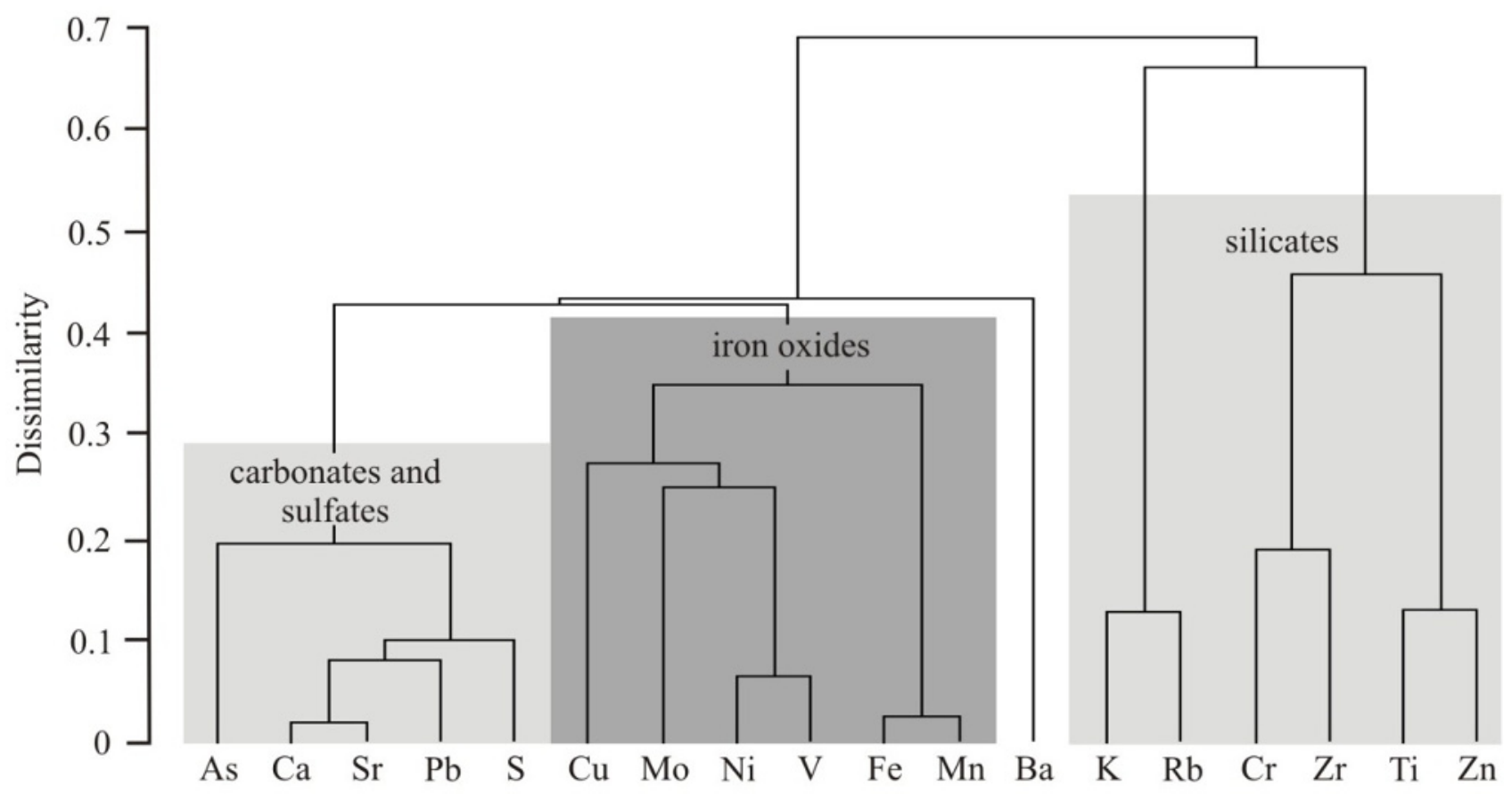

Fig. 1. The results of hierarchical cluster analyses show four element groups with potentially common host phases. 
Table 1. Linear correlation coefficients $(p=0.05)$ calculated for different magnetic properties and heavy metals concentrations in the studied samples

\begin{tabular}{lccccccccc}
\hline & $\mathrm{Cr}$ & $\mathrm{Cu}$ & $\mathrm{Fe}$ & $\mathrm{Mn}$ & $\mathrm{Mo}$ & $\mathrm{Ni}$ & $\mathrm{Pb}$ & $\mathrm{V}$ & $\mathrm{Zn}$ \\
\hline Apparent susceptibility at low frequency & 0.30 & 0.62 & 0.96 & 0.92 & 0.76 & 0.18 & 0.29 & -0.22 & -0.53 \\
Apparent susceptibility at high frequency & 0.31 & 0.62 & 0.96 & 0.92 & 0.76 & 0.18 & 0.29 & -0.22 & -0.53 \\
Mass susceptibility & 0.30 & 0.63 & 0.96 & 0.91 & 0.76 & 0.15 & 0.30 & -0.26 & -0.54 \\
\hline
\end{tabular}

phases are mostly magnetite (up to $15 \%$ ), amorphous organic matter, gypsum (around 5\%) and halite (up to $10 \%)$. The amount of amorphous materials may be as high as $40 \%$ in the samples, which is composed both of soot and debris of plant and animal remains.

The chemical composition of the samples is in good agreement with their mineralogical composition. The concentrations of most of the studied elements can be found in the range of natural geological formations. However, among the nine heavy metals studied, a few of them show significant enrichment as compared to such formations. The generally high amounts of $\mathrm{Zn}, \mathrm{Pb}, \mathrm{Cu}$ and Mo suggest their anthropogenic origin. They can be characterized by the following concentration ranges: $1342-19046 \mathrm{mg} / \mathrm{kg}$ for $\mathrm{Zn}, 330-3597 \mathrm{mg} / \mathrm{kg}$ for $\mathrm{Pb}$, $394-699 \mathrm{mg} / \mathrm{kg}$ for $\mathrm{Cu}$ and $13-53 \mathrm{mg} / \mathrm{kg}$ for Mo. Contrarily, heavy metals with concentrations much more closer to their natural abundances are as follows: $\mathrm{Cr}$ with $97-270 \mathrm{mg} / \mathrm{kg}$, Mn with 834-2105 mg/kg, Ni with 80-190 $\mathrm{mg} / \mathrm{kg}$, V with $119-407 \mathrm{mg} / \mathrm{kg}$ and Fe with $4.8-9.2 \%$.

Hierarchical cluster analyses based on the linear correlation of element concentrations show the following element groups with potentially common host phases: 1) elements bound to carbonates and sulfates, such as $\mathrm{Ca}, \mathrm{Sr}$, $\mathrm{As}, \mathrm{Pb}, \mathrm{S} ; 2$ ) elements bound to iron oxides, such as $\mathrm{Fe}$, $\mathrm{Mn}, \mathrm{Cu}, \mathrm{Mo}, \mathrm{Ni}, \mathrm{V}$; 3) elements bound to both carbonates/sulfates and iron oxides, such as $\mathrm{Ba}$; and 4) elements bound to silicates (probably mostly clay minerals and mica), such as $\mathrm{K}, \mathrm{Rb}, \mathrm{Cr}, \mathrm{Ti}, \mathrm{Zn}, \mathrm{Zr}$ (Figure 1). These results suggest that elements showing significant enrichment can be associated to different elements with varying origin.

Magnetic properties of the studied samples show large variation. Apparent susceptibility values were found to be between 383-2316 and 351-2098 $10^{-6}$ SI at low and high frequencies, respectively. Mass susceptibility values varied between 7.68 and $45.1610^{-6}$ $\mathrm{kg} / \mathrm{m}^{3}$, which are similar values as those for PM10 samples. These analyses show that magnetite particles are present as the mixture of superparamagnetic $(<30 \mathrm{~nm})$ and ferromagnetic $(30-100 \quad \mathrm{~nm})$ grains. Superparamagnetic contribution is higher at lower than higher mass susceptibilities (decrease of the susceptibility for the same sample at high frequency ranges from 2.7 to $4.3 \%$ ). Both mass and apparent susceptibilities show strong linear correlation with the concentration of Fe suggesting that iron is almost solely present in magnetite. These values are also correlated with $\mathrm{Mn}(\mathrm{r}=0.91)$, Mo $(\mathrm{r}=0.76)$ and $\mathrm{Cu}(\mathrm{r}=0.63)$ correlations showing the strong association of these metals with magnetite. The presence of other strongly enriched metals, such as $\mathrm{Pb}$ and $\mathrm{Zn}$ in magnetite cannot be excluded, but these metals must be associated also with other phases.

Transmission electron microscopy analyses were carried out to study the association of heavy metals showing enrichment in the studied samples with individual dust particles. They showed that soot aggregates consisting of nano-sized (few tens of nm) soot particles are the dominant phases in the samples. This is in good agreement with the presence of high amounts of $\mathrm{X}$-ray-amorphous (organic) material found in the samples.

The most important heavy metal bearing mineral phases were found to be spherular or xenomorphic magnetite particles. They sometimes contain 2-3 wt $\%$ $\mathrm{Pb}$ and $\mathrm{Zn}$. These magnetite particles often form aggregates and are closely associated with soot and/or clay minerals (Figure 2a). In samples with high magnetite content heavy metal-free magnetite spherules up to a few micrometer sizes also appeared. Samples also contain ferrihydrite and probably hematite, but their amount is much lower than that of magnetite.

Layer silicate particles often contain heavy metals in the studied samples (Figure 2b). Clay minerals and mica particles were also found to contain significant amount of $\mathrm{Zn}$ (up to $5 \mathrm{wt} \%$ ) and also $\mathrm{Pb}$ in much smaller amount (up to $0.41 \mathrm{wt} \%$ ).

Additionally, single $\mathrm{ZnO}$ and $\mathrm{ZnCO}_{3}$ (smithsonite) particles were also found in the sample with highest $\mathrm{Zn}$ content (collected at the UP thermal station). Again a single aggregate consisting of iron oxide and calcium carbonate was also found to contain significant amount of $\mathrm{Pb}(4.88 \mathrm{wt} \%)$. This may suggest the presence of $\mathrm{Pb}$ also in carbonates. However, more direct data is needed to support this latter supposition.

\section{Conclusions}

Total suspended particulate (TSP) matter samples from Budapest, Hungary show significant enrichment in $\mathrm{Zn}$, $\mathrm{Pb}, \mathrm{Cu}$ and Mo. Statistical analyses based on their concentrations, that of other elements and the magnetic properties of TSP showed that they can be associated to not only one common anthropogenic phase. The nano-sized magnetite particles are supposed to be the major host for $\mathrm{Cu}$ and Mo. Additionally, transmission electron microscopy analyses showed that such particles 

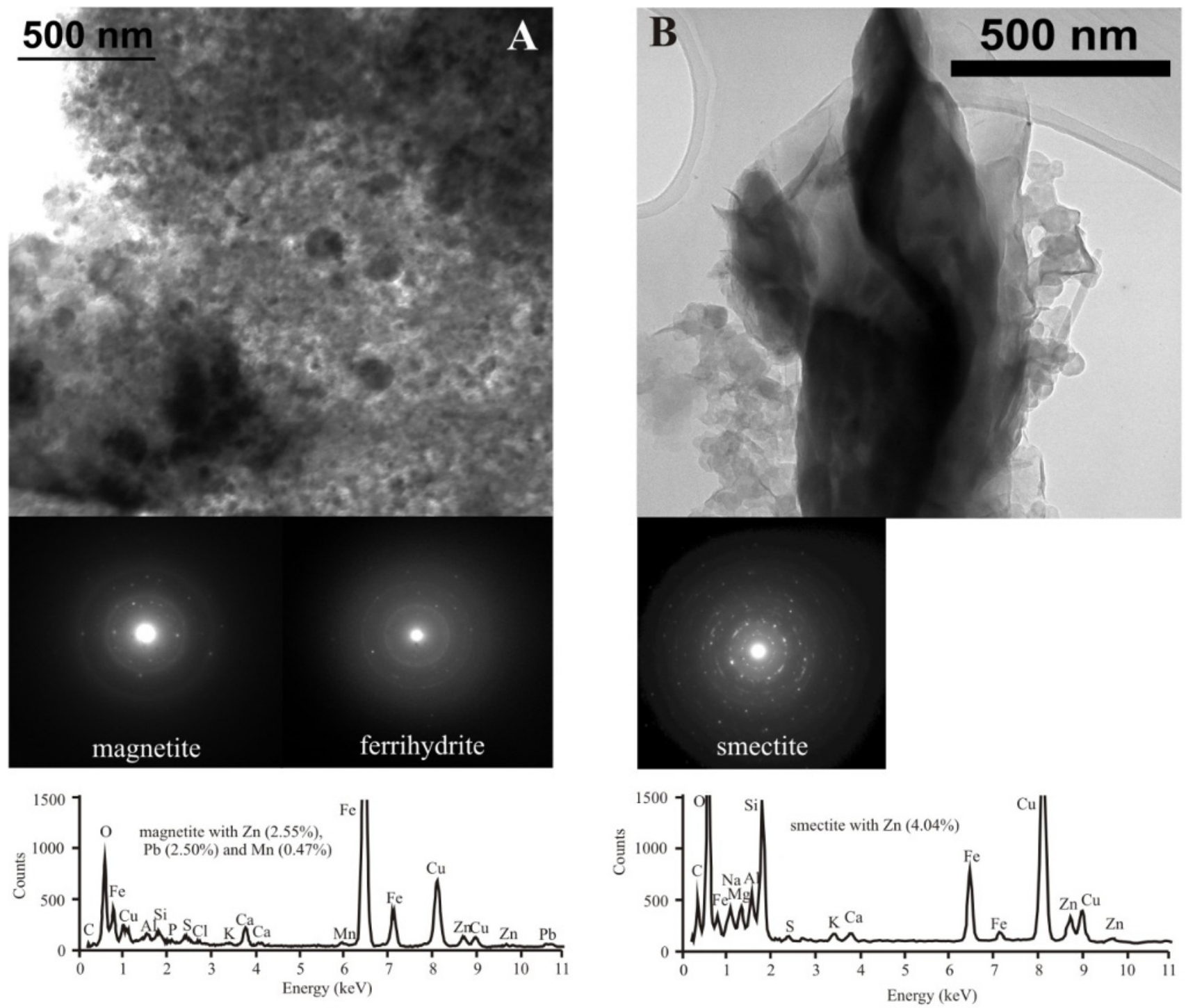

Fig. 2. Microphotographs of the most common heavy metal bearing phases of the TSP samples. According to SAED measurements, the aggregate on the top left picture (A) contains primarily magnetite. Diffraction ring implies the presence of minor amount of ferrihydrite, as well. Below that, the energy dispersive spectrum of a magnetite particle with significant amount of $\mathrm{Zn}, \mathrm{Pn}$ and $\mathrm{Mn}$ is presented. On the top right picture (B), a smectite particle is shown with significant $\mathrm{Zn}$ content (see EDS spectrum).

also may contain significant amount of $\mathrm{Zn}$ and $\mathrm{Pb}$. However, these latter metals may be associated also with layer silicates and carbonates. Moreover, $\mathrm{Zn}$ also appeared as major phase constituent in carbonates and oxides.Additionally, transmission electron microscopy analyses showed that such particles also may contain significant amount of $\mathrm{Zn}$ and $\mathrm{Pb}$. However, these latter metals may be associated also with layer silicates and carbonates. Moreover, $\mathrm{Zn}$ also appeared as major phase constituent in carbonates and oxides.

Magnetite particles are resistant to weathering releasing its toxic components slowly to the environment, while layer silicates (and carbonates) may be the potential source of mobile toxic metals in the TSP from Budapest.

\section{Acknowledgements}

The authors thank the financial supports providing from the Hungarian Scientific Research Fund (OTKA K76317 and K75395). 